International Journal of Pure and Applied Mathematics

Volume 106 No. 1 2016, 49-58

ISSN: 1311-8080 (printed version); ISSN: 1314-3395 (on-line version)

url: http://www.ijpam.eu

doi: 10.12732/ijpam.v106i1.4

ijpam.eu

\title{
FIXED POINT RESULTS FOR WEAK CONTRACTIONS IN GENERALIZED CONE METRIC SPACES
}

\author{
Sunanda R. Patil ${ }^{1}$, J.N. Salunke ${ }^{2}$ \\ ${ }^{1}$ K.C.E.Society's \\ College of Engineering and Inf. Technology \\ Jalgaon, 425001, Maharashtra, INDIA \\ ${ }^{2}$ Department of Mathematics \\ Swami Ramanand Teerth Marathwada University \\ Nanded, 431606, Maharashtra, INDIA
}

\begin{abstract}
In this paper, we obtain some fixed point results for weak contractions in generalized cone metric spaces. We extend the results for generalized metric spaces.

An example is provided to illustrate the obtained results.

AMS Subject Classification: 47H10, 54H 25

Key Words: generalized cone metric space, coincidence point, weakly compatible, common fixed point, cone metric
\end{abstract}

\section{Introduction}

A new structure for generalized metric spaces called G-metric spaces was introduced by Z. Mustafa and B. Sims in [13]. In [3], [14], [15], more results in these spaces have been proved.

Later cone metric spaces were introduced by G. Huang and X. Zhang (see [11]) by replacing the set of real numbers by an ordered Banach space and they obtained fixed point theorems for mappings satisfying various conditions. Rezapour and Hamlbrani (see [18]) obtained fixed point results by omitting the condition of normality of the cone in cone metric spaces.

\footnotetext{
Received: July 19, 2015

(c) 2016 Academic Publications, Ltd.

Published: February 1, 2016

url: www.acadpubl.eu
}

${ }^{\S}$ Correspondence author 
As generalizations of G-metric spaces and cone metric spaces I. Beg, M. Abbas and T. Nazir in [6], [7] introduced G-cone metric spaces. They gave the topological properties of such spaces and also proved some fixed point results.

The concept of weak contraction maps was introduced by Ya I. Alber and S. Guerre-Delabriere, see [5], for fixed points in Hilbert spaces. This concept was extended to metric spaces by B.E. Rhoades, see [19].

Definition 1.1. A mapping $T: X \rightarrow X$ where $(X, d)$ is a metric space is said to be a weak contraction if

$$
d(T x, T y) \leq d(x, y)-\phi(d(x, y))
$$

where $x, y \in X$ and $\phi:[0, \infty) \rightarrow[0, \infty)$ is continuous and nondecreasing function such that $\phi(t)=0$ if and only if $t=0$.

Some more generalized results for weak contractions in metric spaces have been obtained by P. Dutta and B. Choudhury (see [10]), Q. Zhang and Y. Song (see [21]). Also B. Choudhury and N. Metiya (see [8]), Hui-Sheng Ding et al (see [9]) and W. Sintunavarat and P. Kumam (see [20]) proved fixed point results for such maps in cone metric spaces.

Fixed point results for weak contractions in G-metric spaces were obtained by C.T. Aage and J.N. Salunke see [1]. They proved the following result.

Theorem 1.2. (see [1]) Let $(X, G)$ be a complete G-metric space and let $T: X \times X$ be a mapping satisfying

$$
G(T x, T y, T z) \leq G(x, y, z)-\phi G(x, y, z),
$$

for all $x, y, z \in X$. If $\phi:[0, \infty) \rightarrow[0, \infty)$ is a continuous and nondecreasing function with $\phi^{-1}(0)=0, \phi(t)>0$ for all $t \in(0, \infty)$, then $T$ has a unique fixed point in $X$.

Our aim in this paper is to extend these results to the G-cone metric space.

\section{Preliminaries}

Let $E$ be a Banach space and $P$ a subset of $E$. $P$ is called a cone if and only if:

(i) $P$ is closed, nonempty, and $P \neq\{0\}$.

(ii) $a, b \in \mathbb{R}, a, b \geq 0, x, y \in P \Rightarrow a x+b y \in P$.

(iii) $x \in P$ and $-x \in P \Rightarrow x=0$. 
Given a cone $P \subset E$ we define a partial ordering $\leq$ with respect to $P$ by:

$$
x \leq y \Rightarrow y-x \in P
$$

We shall write $x<y$ to indicate that $x \leq y$ but $x \neq y$, while $x \ll y$ will stand for $y-x \in \operatorname{int} P$,int $P$ denotes the interior of $P$.

The cone $P$ is called normal if there is a number $k>0$ such that for all $x, y \in E$,

, where $\|$.$\| is the norm in E$.

$$
0 \leq x \leq y \Rightarrow\|x\| \leq k\|y\|
$$

The least positive number satisfying the above inequality is called the normal constant of $P$.

In the following we always suppose that $E$ is a Banach space, $P$ is a cone in $E$ with $\operatorname{int} P \neq \phi$ and $\leq$ is partial ordering with respect to $P$.

Definition 2.1. (see [6]) Let $X$ be a nonempty set and suppose $G$ : $X \times X \times X \rightarrow E$ satisfies:

(G1) $\mathrm{G}(\mathrm{x}, \mathrm{y}, \mathrm{z})=0$ if $\mathrm{x}=\mathrm{y}=\mathrm{z}$,

(G2) $0<G(x, x, y)$; whenever $x \neq y, \quad \forall x, y \in X$,

(G3) $G(x, x, y) \leq G(x, y, z)$; whenever $y \neq z$,

(G4) $G(x, y, z)=G(x, z, y)=G(y, x, z)=\cdots$ (Symmetry in all three variables),

(G5) $G(x, y, z) \leq G(x, a, a)+G(a, y, z), \quad \forall x, y, z, a \in X$.

Then $\mathrm{G}$ is called a Generalized cone metric on $X$, and $X$ is called a Generalized cone metric space or a G-cone metric space.

Definition 2.2. (see [6]) A G-cone metric space is said to be symmetric if

$$
G(x, y, y)=G(y, x, x), \quad \forall x, y \in X
$$

Following are examples of symmetric and nonsymmetric G-cone metric spaces.

Example 2.3. (see $[6])$ Let $(X, d)$ be a cone metric space. Define $G$ : $X \times X \times X \rightarrow E$, by

$$
G(x, y, z)=G(x, y)+G(y, z)+G(z, x)
$$


Example 2.4. (see [6]) Let $X=a, b, E=\mathbb{R}^{3}, P=\{(x, y, z) \in E \mid x, y, z \geq$ $0\}$. Define $G: X \times X \times X \rightarrow E$ by

$$
\begin{aligned}
& G(a, a, a)=(0,0,0)=G(b, b, b), \\
& G(a, b, b)=(0,1,1)=G(b, a, b)=G(b, b, a), \\
& G(b, a, a)=(0,1,0)=G(a, b, a)=G(a, b, a) .
\end{aligned}
$$

Here $X$ is nonsymmetric G-cone metric space since $G(a, a, b) \neq G(a, b, b)$.

Remark 2.5. (see [6]) If $E$ is a real Banach space with cone $P$ and if $a \leq \lambda a$ where $a \in P$ and $0<\lambda<1$ then $a=0$.

Definition 2.6. (see [6]) Let $X$ be a G-cone metric space and let $\left\{x_{n}\right\}$ be a sequence in $X .\left\{x_{n}\right\}$ is said to be Cauchy if for every $c \in E$, with $0 \ll c$, there is $N$ such that for $n, m, l>N, G\left(x_{n}, x_{m}, x_{l}\right) \ll c$.

Definition 2.7. (see [6]) A sequence $\left\{x_{n}\right\}$ in a G-cone metric space $X$ is said to be convergent if for every $c \in E$, with $0 \ll c$, there is $N$ such that for $n, m>N, G\left(x_{n}, x_{m}, x\right) \ll c$., for some fixed $x$ in $X$. Here $x$ is called the limit of the sequence $\left\{x_{n}\right\}$.

Lemma 2.8. (see [6]) If $X$ is a G-cone metric space,then the following are equivalent:

(i) $\left\{x_{n}\right\}$ converges to $x$

(ii) $G\left(x_{n}, x_{n}, x\right) \rightarrow 0$ as $n \rightarrow \infty$

(iii) $G\left(x_{n}, x, x\right) \rightarrow 0$ as $n \rightarrow \infty$

(iv) $G\left(x_{m}, x_{n}, x\right) \rightarrow 0$ as $n \rightarrow \infty$

Lemma 2.9. (see [6]) Let $\left\{x_{n}\right\}$ be a sequence in a G-cone metric space $X$ and $x \in X$. If $\left\{x_{n}\right\}$ converges to $x$ and also to $y$, then $x=y$.

Lemma 2.10. (see [6]) Let $\left\{x_{n}\right\}$ be a sequence in a $G$-cone metric space $X$ and if $\left\{x_{n}\right\}$ is a Cauchy sequence in $X$, then $G\left(x_{m}, x_{n}, x_{l}\right) \rightarrow 0$, as $m, n, l \rightarrow \infty$.

Lemma 2.11. (see [6]) Let $\left\{x_{n}\right\}$ be a sequence in a G-cone metric space $X$ and let $x \in X$. If $\left\{x_{n}\right\}$ converges to $x \in X$, then $\left\{x_{n}\right\}$ is a Cauchy sequence.

Lemma 2.12. (see [6]) Let $X$ be a G-cone metric space, $\left\{x_{m}\right\},\left\{y_{n}\right\}$ and $\left\{z_{l}\right\}$,be sequences in $X$ such that $x_{m} \rightarrow x, y_{n} \rightarrow y$ and $z_{l} \rightarrow z$, then $G\left(x_{m}, y_{n}, z_{l}\right) \rightarrow G(x, y, z)$ as $m, n, l \rightarrow \infty$. 
Definition 2.13. (see [4]) Let $T$ and $S$ be selfmappings of a set $X$. If $T x=S x=w$,for some $x \in X$, then $x$ is called the coincidence point and $w$ the point of coincidence of $T$ and $S$.

Definition 2.14. Two self mappings $T$ and $S$ are said to be weakly compatible if they commute at their coincidence points, that is $T x=S x$ implies that $T S x=S T x$.

Proposition 2.15. (see [4]) If $T$ and $S$ are weakly compatible self maps of a nonempty set $X$ such that they have a unique point of coincidence, i.e. $T x=S x=y$, then $y$ is the unique common fixed point of $T$ and $S$.

Definition 2.16. Let $(X, G)$ be a G-cone metric space over a solid cone $P$. Denote $\Phi$, the class of functions $\phi: \operatorname{int} P \cup\{\theta\} \rightarrow \operatorname{int} P \cup\{\theta\}$ satisfying the following conditions:

(1) $\phi(t)=\theta$ iff $t=\theta$;

(2) $\phi(t) \ll t$, for $t \in$ int $P$;

(3) for all $t \in$ intP and $x, y, z \in X$, either $\phi(t) \leq G(x, y, z)$ or $G(x, y, z) \ll$ $\phi(t)$.

\section{Main Results}

Theorem 3.1. Let $(X, G)$ be a $G$-cone metric space over a regular cone $P$ such that $G(x, y, z) \in \operatorname{int} P$ for $x, y, z \in X$ where $x \neq y \neq z$ and let $T, S$ be selfmaps in $X$ satisfying

$$
G(T x, T y, T z) \leq G(S x, S y, S z)-\phi G(S x, S y, S z)
$$

for all $x, y, z \in X$ where $\phi \in \Phi$ is continuous. If $T(X) \subseteq S(X)$ and any one of these subsets is complete, then $T$ and $S$ have a unique point of coincidence. If $T$ and $S$ are weakly compatible, then they have a unique common fixed point.

Proof. Let $x_{0} \in X$ be arbitrary. Since $T(X) \subseteq S(X)$, we construct sequence $\left\{y_{n}\right\}$ in $X$ such that $T x_{n}=S x_{n+1}=y_{n}$, say, $n \in \mathbb{N}$.

If $y_{n}=y_{n+1}$ for some $n \in \mathbb{N}$, then $S x_{n+1}=T x_{n+1}$ and $T$ and $S$ have a point of coincidence. Let us suppose $y_{n} \neq y_{n+1}$ for all $n \in \mathbb{N}$. By (1) we have

$$
\begin{aligned}
G\left(y_{n}, y_{n+1}, y_{n+1}\right) & =G\left(T x_{n}, T x_{n+1}, T x_{n+1}\right) \\
& \leq G\left(S x_{n}, S x_{n+1}, S x_{n+1}\right)-\phi G\left(S x_{n}, S x_{n+1}, S x_{n+1}\right)
\end{aligned}
$$


By property of $\phi$,

$$
G\left(y_{n}, y_{n+1}, y_{n+1}\right) \leq G\left(y_{n-1}, y_{n}, y_{n}\right)
$$

for all $n \in \mathbb{N}$. Similarly we can also show

$$
G\left(y_{n-1}, y_{n}, y_{n}\right) \leq G\left(y_{n-2}, y_{n-1}, y_{n-1}\right)
$$

Hence $G\left(y_{n}, y_{n+1}, y_{n+1}\right)$ is monotone decreasing and there exists $r \geq \theta$ such that

$$
G\left(y_{n}, y_{n+1}, y_{n+1}\right) \rightarrow r \text { as } n \rightarrow \infty .
$$

As $n \rightarrow \infty$ in (2), we obtain

$$
r \leq r-\phi(r)
$$

which is a contradiction unless $r=\theta$.

Hence,

$$
\lim _{n \rightarrow \infty} G\left(y_{n}, y_{n+1}, y_{n+1}\right)=\theta \text {. }
$$

Now we will prove that $\left\{y_{n}\right\}$ is a Cauchy sequence. Suppose it is not. Then there exists $c \in \operatorname{int} P$ for which we can find subsequences $\left\{y_{n(k)}\right\}$ and $\left\{y_{m(k)}\right\}$ of $\left\{y_{n}\right\}$ with $n(k)>m(k)>k$ such that

$$
G\left(y_{n(k)}, y_{m(k)}, y_{m(k)}\right) \geq \phi(c) .
$$

Further, corresponding to each $m(k)$, we can choose $n(k)$, such that it is the smallest integer with $n(k)>m(k)$ satisfying (5). Then we have

$$
G\left(y_{n(k)}, y_{m(k)}, y_{m(k)}\right) \ll \phi(c) .
$$

Using (5) and (6) we obtain

$$
\begin{aligned}
\phi(c) & \leq G\left(y_{n(k)}, y_{m(k)}, y_{m(k)}\right) \\
& \leq G\left(y_{n(k)}, y_{n(k)-1}, y_{n(k)-1}\right)+G\left(y_{n(k)-1}, y_{m(k)}, y_{m(k)}\right) \\
& \leq G\left(y_{n(k)}, y_{n(k)-1}, y_{n(k)-1}\right)+\phi(c) .
\end{aligned}
$$

Letting $k \rightarrow \infty$ in the inequality above and using (4) we receive

$$
\lim _{n \rightarrow \infty} G\left(y_{n(k)}, y_{m(k)}, y_{m(k)}\right)=\phi(c) \text {. }
$$

Therefore,

$$
G\left(y_{n(k)-1}, y_{m(k)-1}, y_{m(k)-1}\right) \leq G\left(y_{n(k)-1}, y_{n(k)}, y_{n(k)}\right)
$$




$$
\begin{aligned}
& +G\left(y_{n(k)}, y_{m(k)}, y_{m(k)}\right) \\
& +G\left(y_{m(k)}, y_{m(k)-1}, y_{m(k)-1}\right) .
\end{aligned}
$$

Again letting $k \rightarrow \infty$ and using inequalities (4) and (7), we have

$$
\lim _{k \rightarrow \infty} G\left(y_{n(k)-1}, y_{m(k)-1}, y_{m(k)-1}\right)=\phi(c) .
$$

From (1) we receive

$$
\begin{aligned}
G\left(y_{n(k)}, y_{m(k)}, y_{m(k)}\right) & =G\left(T x_{n(k)}, T x_{m(k)}, T x_{m(k)}\right) \\
& \leq G\left(S x_{n(k)}, S x_{m(k)}, S x_{m(k)}\right) \\
& -\phi G\left(S x_{n(k)}, S x_{m(k)}, S x_{m(k)}\right) \\
& \leq G\left(y_{n(k)-1}, y_{m(k)-1}, y_{m(k)-1}\right) \\
& -\phi G\left(y_{n(k)-1}, y_{m(k)-1}, y_{m(k)-1}\right) .
\end{aligned}
$$

Letting $k \rightarrow \infty$ in above inequality,using (7),(8) and the continuity of $\phi$,we get

$$
\phi(c) \leq \phi(c)-\phi(\phi(c))
$$

By properties of the function $\phi$, it is obvious that $c=\theta$, a contradiction. Hence $\left\{y_{n}\right\}$ is a Cauchy sequence in $X$.

By our assumption,there exists some $p \in X$ such that $\lim _{n \rightarrow \infty} y_{n}=S p$. We prove that $T p=S p$.

From (1),

$$
\begin{aligned}
G\left(y_{n}, T p, T p\right) & =G\left(T x_{n}, T p, T p\right) \\
& \leq G\left(S x_{n}, S p, S p\right)-\phi G\left(S x_{n}, S p, S p\right) \\
& =G\left(y_{n-1}, S p, S p\right)-\phi G\left(y_{n-1}, S p, S p\right)
\end{aligned}
$$

On letting $n \rightarrow \infty$ and using the property of $\phi$ we have $G(S p, T p, T p) \leq$ $\theta$. Hence $G(S p, T p, T p)=\theta$ and $T p=S p=q$, say, then $q$ is the point of coincidence of $T$ and $S$.

To prove that the point of coincidence is unique, suppose there is another point $v \in X$, such that $T u=S u=v$ for some $u \in X$.

Consider,

$$
\begin{aligned}
G(v, q, q) & =G(T u, T p, T p) \\
& \leq G(S u, S p, S p)-\phi G(S u, S p, S p) \\
& \leq G(v, q, q)-\phi G(v, q, q)
\end{aligned}
$$


Thus by property of $\phi, G(v, q, q)=\theta$ and $q=v$.

It follows from Proposition(2.15) that if $T$ and $S$ are weakly compatible, then they have a unique common fixed point.

Example 3.2. Let $E=\mathbb{R}$, and $P=\{x \in \mathbb{R}, x \geq 0\}$ be a cone. Let $X=[0,1]$ and $G: X \times X \times X \rightarrow P$ be defined by

$$
G(x, y, z)=d(x, y)+d(y, z)+d(z, x)
$$

where $d(x, y)=|x-y|$. Then $(X, G)$ is a G-cone metric space.

Define $T, S: X \rightarrow X$ by $T x=\frac{x}{3}$ and $S x=\frac{4 x}{3}$ and $\phi(t)=\frac{t}{3}, \forall t>0$.

Then:

$$
\begin{aligned}
G(T x, T y, T z) & =|T x-T y|+|T y-T z|+|T z-T x| \\
& =\left|\frac{x}{3}-\frac{y}{3}\right|+\left|\frac{y}{3}-\frac{z}{3}\right|+\left|\frac{z}{3}-\frac{x}{3}\right| \\
& =\frac{1}{3}\{|x-y|+|y-z|+|z-x|\} .
\end{aligned}
$$

Similarly

$$
G(S x, S y, S z)=\frac{4}{3}\{|x-y|+|y-z|+|z-x|\}
$$

and

$$
\phi[G(S x, S y, S z)]=\frac{4}{9}\{|x-y|+|y-z|+|z-x|\}
$$

Therefore

$$
G(T x, T y, T z) \leq G(S x, S y, S z)-\phi G(S x, S y, S z)
$$

Clearly conditions of Theorem 3.1 are fulfilled and $T$ and $S$ have a unique common fixed point which is 0 .

Corollary 3.3. Let $(X, G)$ be a $G$-cone metric space and let $T$ be a selfmap in $X$ satisfying

$$
G(T x, T y, T z) \leq G(x, y, z)-\phi G(x, y, z),
$$

for all $x, y, z \in X$ where $\phi \in \Phi$ is continuous. If $T(X)$ is complete, then $T$ has a unique fixed point in $X$.

Proof. Taking $S=I$ in Theorem 3.1, we get the result. 


\section{References}

[1] Chintaman T.Aage,Jagannath N.Salunke,Fixed Points For Weak Contractions In G Metric Spaces, Applied mathematices E-Notes12,(2012),23-28.

[2] C. T.Aage,J. N. Salunke,Fixed points of $(\psi, \phi)$-weak contractions in cone metric spaces, Ann. Funct. Anal.2(1)(2011),59-71.

[3] M. Abbas,B. E. Rhoades, Common fixed point results for non commuting mappings without continuity in generalized metric spaces, Applied Math. and Computation,215(2009),262269.

[4] M.Abbas,G. Jungck,Common fixed point results for noncommuting mappings without continuity in cone metric spaces, Journal of Mathematical Analysis and Applications,341.1,(2008),416-420.

[5] Ya I.Alber,Sylvie Guerre-Delabriere,Principle of weakly contractive maps in Hilbert spaces, New Results in Operator Theory and Its Applications Birkhuser Basel,(1997),722.

[6] I.Beg, M.Abbas,T.Nazir, Generalized Cone Metric Spaces, The Journal of Nonlinear Science And Applications,1,(2010),21-31.

[7] Ismat Beg, Mujahid Abbas,Talat Nazir,Common fixed point results in G cone metric spaces, J. Advanced Research in Pure Mathematics,2.4,(2010),94-109.

[8] Binayak S.Choudhury ,N. Metiya,Fixed points of weak contractions in cone metric spaces, Nonlinear Analysis: Theory, Methods and Applications,72.3(2010),1589-1593.

[9] Hui-Sheng Ding,Zoran Kadelburg,Erdal Karapnar,Stojan Radenovic,Common fixed points of weak contractions in cone metric spaces Abstract and Applied Analysis., Vol.2012,(2012), Article ID 793862,18 pages.

[10] P.N.Dutta,B.S.Choudhury, A generalisation of contraction principle in metric spaces Fixed Point Theory and Applications Volume.2008,(2008), Article ID 406368,8 pages.

[11] Long-Guang Huang, Xian Zhang, Cone metric spaces and fixed point theorems of contractive mappings, J. Math. Anal. Appl.,332(2007) 1468-1476.

[12] Kanayo Stella Eke, Common Fixed Point Results of Weakly Compatible Maps in G-metric Spaces, British Journal of Mathematics and Computer Science,5(3)(2015),341-348.

[13] Z. Mustafa,B. Sims, A New Approach to Generalized Metric Spaces, Journal of Nonlinear and Convex Analysis,7(2)(2006), 289-297.

[14] Zead Mustafa,Hamed Obiedat,Fadi Awawdeh, Some Fixed Point Theorem for Mapping on Complete G- metric Spaces, Fixed Point Theory and Applications,Volume.2008,(2008)Article ID 189870,12 pages.

[15] Z.Mustafa,W. Shatanawi,Existence of fixed points results in G metric-spaces, Int.J. Math. Math. Sci.,Volume 2009,(2009) Article ID 283028,10 pages.

[16] Sunanda R.Patil,J.N.Salunke,Expansion Mapping Theorems in G-cone Metric Spaces,Int. Journal of Math. Analysis,6(44),(2012),2147 - 2158.

[17] Ovidiu Popescu,Fixed points for $(\psi, \phi)$-weak contractions, Applied Mathematics Letters,24(1),(2011),1-4.

[18] S.Rezapour,R.Hamlbarani, Some note on the paper 'Cone metric spaces and fixed point theorems of contractive mappings', J.Math.Anal.Appl.,345,(2008),719-724. 
[19] B.E.Rhoades,Some theorems on weakly contractive maps, Nonlinear Analysis: Theory, Methods and Applications,47(4),(2001)2683-2693.

[20] W. Sintunavarat,P. Kumam,Common fixed points of f-weak contractions in cone metric spaces, Bulletin of the Iranian Mathematical Society,38(2)(2012),293-303.

[21] Q.Zhang,Y.Song,Fixed point theory for generalized $\phi$-weak contractions, Applied Mathematics Letters,22(1)(2009),75-78. 